\title{
Effects of GSTAI and GPX3 Polymorphisms on the Risk of Schizophrenia in Chinese Han Population
}

This article was published in the following Dove Press journal:

Neuropsychiatric Disease and Treatment

\author{
Chao Liu' \\ Sijia Song ${ }^{2}$ \\ Junkai Zhang' \\ Xiao $\mathrm{Li}^{\prime}$ \\ Huijie Gao' \\ 'College of Pharmacy, Jining Medical \\ University, Rizhao, Shandong, People's \\ Republic of China; ${ }^{2}$ Rizhao Mental Health \\ Center, Rizhao, Shandong, People's \\ Republic of China
}

Purpose: Several lines of evidence support the fact that the presence of oxidative stress plays an important role in the pathophysiological mechanisms of schizophrenia (SCZ). The glutathione peroxidases (GPXs) and glutathione S-transferases (GSTs) are the major antioxidant enzymes. Polymorphic variants of $G P X$ and GST can affect the antioxidant activities of their encoded enzymes. This study explored the possible associations of the GSTA1 and GPX3 gene polymorphisms and schizophrenia in Chinese Han population.

Methods: DNA from 648 healthy controls and 617 schizophrenic patients was genotyped for single-nucleotide polymorphisms (SNPs) rs3957357 in GSTA1 and rs736775 in GPX3 using a PCR-LDR genotyping assay. The $\chi^{2}$ test compared differences in genetic distributions between the two groups in a case-control study. The generalized multifactor dimensionality reduction (GMDR) was used to explore the interaction between the GSTA1 gene and the GPX3 gene on the risk of SCZ.

Results: Significant differences in allelic and genotypic frequencies of GSTA1 rs3957357 were present between SCZ and control groups (GSTA1 rs3957357 $\chi^{2}=6.172, P=0.046$ by genotype, $\chi^{2}=5.847, P=0.016$, odds ratio $=1.329,95 \%$ confidence interval $=1.055-1.674$ by allele). No significant differences in allelic or genotypic frequencies of GPX3 rs736775 were detected between cases and controls (GPX3 rs736775: $\chi^{2}=2.058, P=0.357$ by genotype, $\chi^{2}=1.853, P=0.173$, odds ratio=1.131, 95\% confidence interval $=0.953-1.342$ by allele). Moreover, the GMDR model showed that the interaction between GSTA1 rs3957357 and $G P X 3$ rs736775 was associated significantly with SCZ risk, $P=0.0107$.

Conclusion: Our results suggest that GSTA1 rs3957357 SNP has an effect on the risk of SCZ and the interaction between GSTA1 rs3957357and GPX3 rs736775 may affect the development of SCZ in Chinese Han population. However, these results should be validated by replication in different populations with large sample sizes.

Keywords: oxidative stress, schizophrenia, glutathione peroxidase, glutathione S-transferase, gene polymorphism

\section{Introduction}

Schizophrenia (SCZ) is a complex and severe mental disorder and is the most common among psychotic illness, with a prevalence of around $1 \%$ in the worldwide population. ${ }^{1-3}$ Although the detailed mechanisms underlying the pathophysiology of SCZ is unknown for certain, multiple pieces of evidence illustrated that a complex interaction between genetic background and environmental factors was likely to be involved in the development of SCZ.,

Dopamine (DA) is the principal neurotransmitter in the brain and plays a significant role in the functions of neurons. However, the oxidative metabolites of dopamine are hydrogen peroxide $\left(\mathrm{H}_{2} \mathrm{O}_{2}\right)$ and DA quinones, which are the principal
Correspondence: Huijie Gao

College of Pharmacy, Jining Medical

University, 669 Xueyuan Road, Rizhao

276826, People's Republic of China

Tel +86 I59540I4646

Email mianyigao@I63.com
Neuropsychiatric Disease and Treatment 2020:16 II3-II8

I I3

(c) (i) @ $\odot 2020$ Liu et al. This work is published and licensed by Dove Medical Press Limited. The full terms of this license are available at https://www.dovepress.com/terms.php cc. permission for commercial use of this work, please see paragraphs 4.2 and 5 of our Terms (https://www.dovepress.com/terms.php). 
source of reactive oxygen species (ROS) in the brain. ${ }^{6}$ Oxidative stress arises when the balance between antioxidant activity and the formation of ROS is disrupted, and ROS can cause neuronal inflammation as a consequence of oxidative stress. Interestingly, several studies suggested that neuronal inflammation induced by oxidative stress plays an important role in SCZ pathophysiological mechanisms. $^{7-9}$

Recently, glutathione (GSH) levels were reported to be decreased in the cerebrospinal fluid and in the prefrontal cortex of SCZ patients. ${ }^{10-12}$ Furthermore, some studies showed changes in antioxidant enzyme activity in the plasma and postmortem brain of schizophrenia patients. ${ }^{7,13}$ Taking all these factors into consideration, we had to focus our attention on the role of oxidative stress in the pathophysiology of SCZ through investigating two important antioxidant enzymes: glutathione peroxidases (GPXs) and glutathione S-transferases(GSTs).

GPX family belongs to selenium-dependent peroxidases and plays an important role in protecting cells from oxidative damage by reducing free hydrogen peroxide to water. The GPX3, a member of GPX family, was found to be highly expressed in the prefrontal cortex suggests that $G P X 3$ may be involved in antioxidant activity in the brain. ${ }^{14}$ Human GPX3 is located on chromosome $5 \mathrm{q} 33.1$ and has a common single-nucleotide polymorphism (SNP), $G P X 3$ rs736775. Several studies have suggested the effect of this variant on GPX3 activity and many disorders. ${ }^{15-18}$

GSTs consist of Phase II detoxication enzyme and can catalyze the conjugation of the reduced form of glutathione (GSH) to xenobiotic substrates for the purpose of detoxification. ${ }^{19}$ The GST alpha, a member of GSTs family, is located in chromosome 6 and shows an important detoxifying activity that protects the cell from ROS. GST alpha 1 (GSTA1) represents one of the most abundant alpha-class GST isoenzymes. In addition, GSTA1 can also inactivate quinones. $^{20} \mathrm{SNP}$ rs3957357 in GSTA1 is just located in the promoter region of GSTA1 genes, and several studies suggested the pathogenic effects of this variant in many disorders. ${ }^{21,22}$

Although polymorphic variants of oxidative stressrelated candidate genes including GSTP1, GSTT1, GSTM1, GPX1 and GSTA1 have been shown to be risk factors for $\mathrm{SCZ},{ }^{23-25}$ genetic polymorphism vary by race considerably and we, therefore, estimated the possible associations of the GSTA1 rs3957357 and GPX3 rs736775 gene polymorphisms and schizophrenia in the Chinese Han population for the purpose of identifying potential prognostic or predictive tools for the individuals at risk of SCZ.

\section{Methods}

\section{Subjects}

The study was approved by the Ethical Committees of Jining Medical University (2018-YX-005, 2018.02-2023.12) in accordance with the Code of Ethics of the Declaration of Helsinki. The participants were recruited from the Rizhao Mental Health Center and Affiliated Hospital of Jining Medical University and they were original northern Han Chinese individuals. The sample consisted of 617 patients with SCZ (301 men and 316 women, mean age $48.2 \pm 4.8$ years) and 648 healthy controls (312 men and 336 women, mean age: $47.9 \pm 4.6$ years) living in the same geographic area. The patients with SCZ were interviewed by two board-certified psychiatrists according to the Diagnostic and Statistical Manual of Mental Disorders, 4th ed. (DSM-IV) criteria. The normal controls were confirmed to be free from any mental illness by two board-certified psychiatrists. All participants gave written informed consent to participate in the study.

\section{Genetic Studies}

Total genomic DNA was extracted from whole blood using TIANamp Genomic DNA Kit (TIANGEN, China), according to the manufacturer's instructions. Genotyping for SNPs GSTA1 rs3957357 and GPX3 rs736775 was performed using the polymerase chain reaction-ligase detection reaction (PCR-LDR) method. The sequences of primers are listed in Table 1. PCR was performed in a volume of $15 \mu \mathrm{L}$ reaction system, containing $7.5 \mu \mathrm{L} 2 \times$ PCR Master Mix, $2 \mu \mathrm{L}$ Primer mix, and $2 \mu \mathrm{L}$ genomic DNA and DNase-free water. Multiplex PCR amplifications were performed under the following conditions: an initial denaturation at $94^{\circ} \mathrm{C}$ for 3 mins, followed by 35 cycles at $94^{\circ} \mathrm{C}$ for $30 \mathrm{~s}, 55^{\circ} \mathrm{C}$ for $30 \mathrm{~s}, 7^{\circ} \mathrm{C}$ for $30 \mathrm{~s}$, and a terminal extension $72^{\circ} \mathrm{C}$ for 3 mins. After multiplex PCR amplification, the LDR was performed

Table I The Information of Primer of GPX3 rs736775 and GSTA I rs3957357 Polymorphism

\begin{tabular}{|l|l|l|}
\hline Primer Name & Sequence (5'-3') & PCR Length \\
\hline rs736775 & $\begin{array}{l}\text { F:TAAACCCAAGTCCCCTGAGT } \\
\text { R:CTCTTGAGTAATGGTGACGTATCA }\end{array}$ & 96bp \\
\hline rs3957357 & $\begin{array}{l}\text { F:ACAACTGAATTCCAGGTCCTAATG } \\
\text { R:GCCATGAAATGTGTGGGAGT }\end{array}$ & $114 \mathrm{bp}$ \\
\hline
\end{tabular}


in a volume of $10 \mu \mathrm{L}$ reaction system, including $3 \mu \mathrm{L}$ PCR product, $1 \mu \mathrm{L} 10 \times$ Taq DNA ligase buffer, $0.125 \mu \mathrm{L}$ Taq DNA ligase $(40 \mathrm{U} / \mu \mathrm{L}), 2 \mu \mathrm{L}$ Probe mix, and $\mathrm{ddH}{ }_{2} \mathrm{O}$, followed by 30 cycles at $94^{\circ} \mathrm{C}$ for $30 \mathrm{~s}, 56^{\circ} \mathrm{C}$ for 3 mins. The sequences of probes are listed in Table 2. Hence, the final reaction system containing $1 \mu \mathrm{L}$ LDR product and $9 \mu \mathrm{L}$ highly deionized formamide were performed under denaturation at $95^{\circ} \mathrm{C}$ for $3 \mathrm{mins}$, and the genotypes were analyzed by ABI 3730XL sequencer and Genemapper software.

\section{Statistical Analysis}

The $\chi^{2}$ test was used to test the Hardy-Weinberg equilibrium (HWE) of the genotype distribution and to compare the differences in genotypic and allelic frequencies of GSTA1 rs3957357 and GPX3 rs736775 between cases and controls. The degree of relative risk was estimated by odds ratios (ORs) and 95\% confidence intervals (CIs). Statistical analysis in this study was carried out using the Statistical Package (version 21.0 for Windows; SPSS Inc., Chicago, Illinois, USA). Generalized multifactor dimensionality reduction (GMDR Software 0.9, http://www.ssg. uab.edu/gmdr/) analysis was used to explore the interaction between the GSTA1 gene and the GPX3 gene on the risk of SCZ. ${ }^{26}$ The values of testing accuracy, sign test $(P)$ and the cross-validation (CV) consistency score were provided by GMDR analysis. $P<0.05$ was considered to denote statistical significance.

\section{Results}

The genotype distributions of the two tested alleles were in accordance with Hardy-Weinberg equilibrium (for rs 736775, $P=0.17 ;$ rs 3957357, $P=0.08$ ). The allelic and genotypic frequencies of GPX3 rs736775 and GSTA1 rs3957357 in SCZ and control groups are shown in Table 3. Significant differences in allelic and genotypic frequencies of GSTA1 rs3957357 were observed between schizophrenic and control groups. (GSTA1 rs3957357: $\chi^{2}=6.172, P=0.046$ by genotype, $\chi^{2}=5.847, P=0.016$, odds ratio $=1.329,95 \%$ confidence interval $=1.055-1.674$ by allele.) No significant differences in allelic or genotypic frequencies of GPX3 rs 736775 were found between schizophrenic and control groups. (GPX3 rs736775: $\chi^{2}=2.058$, $P=0.357$ by genotype, $\chi^{2}=1.853, \quad P=0.173$, odds ratio $=1.131,95 \%$ confidence interval $=0.953-1.342$ by allele.) Furthermore, additive, dominant and recessive genetic models were used to analyze genotype frequencies of GSTA1 rs3957357 and GPX3 rs736775. Table 4 shows that rs3957357 was the risk factor for SCZ on the basis of

Table 2 The Information of Probe of GPX3 rs736775 and GSTAI rs3957357 Polymorphism

\begin{tabular}{|l|l|l|}
\hline Probe Name & Sequence (5'-3') & LDR Length \\
\hline Rs736775_modify & P- TGCCCTACCCTCAGGGAGGCCTGAC-FAM & \\
\hline rs736775_C & CCTAGGCTCCTTCCACTGCCCCGGC & 50 \\
\hline rs736775_T & CTGCCTAGGCTCCTTCCACTGCCCCGGT & 53 \\
\hline Rs3957357_modify & P- GTCAAGTTAGGGAAAAGCCCTGACTGAC -FAM & \\
\hline rs3957357_A & CTGAATAGTTCTCTCCCACTGAAAGAAGA & 57 \\
\hline rs3957357_G & CTGACTGATAGTTCTCTCCCACTGAAAGAAGG & 60 \\
\hline
\end{tabular}

Table 3 The Comparison of Genotypic and Allelic Frequencies Between SCZ and Control Groups

\begin{tabular}{|c|c|c|c|c|c|c|c|c|c|}
\hline \multirow[t]{2}{*}{ SNP } & \multicolumn{5}{|c|}{ Allelic Test } & \multicolumn{4}{|c|}{ Genotypic Test } \\
\hline & Allele & SCZ/Control & $\mathbf{P}$ & $\chi^{2}$ & OR(95\% Cl) & Genotype & SCZ/Control & $\mathbf{P}$ & $\chi^{2}$ \\
\hline rs3957357 & $\begin{array}{l}\mathrm{G} \\
\mathrm{A}\end{array}$ & $\begin{array}{l}1050 / 1145 \\
|84 / 15|\end{array}$ & 0.016 & 5.847 & $\begin{array}{l}1.329 \\
(1.055-1.674)\end{array}$ & $\begin{array}{l}\text { GG } \\
A G \\
A A\end{array}$ & $\begin{array}{l}442 / 503 \\
166 / 139 \\
9 / 6\end{array}$ & 0.046 & 6.172 \\
\hline rs736775 & $\begin{array}{l}\mathrm{T} \\
\mathrm{C}\end{array}$ & $\begin{array}{l}857 / 933 \\
377 / 363\end{array}$ & 0.173 & 1.853 & $\begin{array}{l}1.131 \\
(0.953-1.342)\end{array}$ & $\begin{array}{l}\mathrm{TT} \\
\mathrm{CT} \\
\mathrm{CC}\end{array}$ & $\begin{array}{l}292 / 331 \\
273 / 271 \\
52 / 46\end{array}$ & 0.357 & 2.058 \\
\hline
\end{tabular}


Table 4 Analysis of the Two SNPs Based on Three Genetic Models

\begin{tabular}{|c|c|c|c|c|c|c|c|c|}
\hline \multirow[t]{2}{*}{ SNP } & \multirow[t]{2}{*}{ Genotype } & \multirow[t]{2}{*}{ SCZ/Control } & \multicolumn{2}{|c|}{ Additive Model } & \multicolumn{2}{|c|}{ Dominant Model } & \multicolumn{2}{|c|}{ Recessive Model } \\
\hline & & & $\mathbf{P}$ & OR(95\% Cl) & $\mathbf{P}$ & OR(95\% Cl) & $\mathbf{P}$ & OR(95\% Cl) \\
\hline rs3957357 & $\begin{array}{l}\text { GG } \\
\text { AG } \\
\text { AA }\end{array}$ & $\begin{array}{l}442 / 503 \\
166 / 139 \\
9 / 6\end{array}$ & 0.31 & $0.59(0.2 \mathrm{I}-\mathrm{I} .66)$ & 0.01 & $0.73(0.56-0.94)$ & 0.38 & $0.63(0.22-1.78)$ \\
\hline rs736775 & $\begin{array}{l}\text { TT } \\
\text { CT } \\
\text { CC }\end{array}$ & $\begin{array}{l}292 / 331 \\
273 / 271 \\
52 / 46\end{array}$ & 0.25 & $\begin{array}{l}0.78 \\
(0.5 I-I .20)\end{array}$ & 0.18 & $0.86(0.69-1.07)$ & 0.38 & $0.83(0.55-1.26)$ \\
\hline
\end{tabular}

dominant models $(P=0.01)$ and rs736775 was not the risk factor for SCZ on the basis of these models (all $P>0.05$ ).

In addition, the interaction between GSTA1 (rs3957357) and GPX3 (rs736775) was analyzed using GMDR software, with testing accuracy of $0.5330, \mathrm{CV}$ consistency of $10 / 10$, and $P=0.0107$. The results showed that the potential gene-gene interaction between GSTA1 and GPX3 was associated with SCZ risk.

\section{Discussion}

It is well known that the oxygen consumption of the brain is the highest in our body and hence generation of ROS increase. Moreover, the oxidative metabolites of dopamine are hydrogen peroxide $\left(\mathrm{H}_{2} \mathrm{O}_{2}\right)$ and DA quinones, which are the principal source of ROS in the brain. ${ }^{6}$ Therefore, the brain is considered particularly vulnerable to ROS. Normally, ROS can be eliminated by the antioxidant system. When the balance between the formation of ROS and intrinsic antioxidant capacity is upset, oxidative metabolite damage to neurons arises. Increasing evidence indicates that oxidative injury to neurons can play important roles in the pathophysiology of neuropsychiatric disorders including schizophrenia. ${ }^{7,8,9}$

The antioxidant system comprises of enzymatic and nonenzymatic antioxidants, and enzymes involved in the antioxidant systems comprise of glutathione peroxidase (GPx), glutathione $\mathrm{S}$ transferase (GST), and so on. Polymorphic variants of GPX and GST may affect their antioxidant activities, contributing to the imbalance of ROS production and antioxidant capacity in SCZ patients. ${ }^{23,24,27}$

GPXs are encoded by the GPX gene family and consist of eight groups, GPX1-8. The GPX3, a member of the GPX family, was found to be highly expressed in the prefrontal cortex suggests that GPX may be involved in antioxidant activity in the brain. The human GPX3 gene is located on chromosome 5q33.1 and multiple GPX3 SNPs have been reported, with rs736775 being one of the most common. For instance, Noci et al demonstrated that GPX3 rs736775 was associated with overall survival in colorectal cancer patients. ${ }^{16}$ Zhang et al also suggested that GPX3 rs736775 was a prognostic marker in patients with gastric cancer. ${ }^{17}$ Another study showed that the increased risk for cardiovascular toxicity among patients was associated with $G P X 3$ rs736775. ${ }^{28}$ Taking these results into consideration, $G P X 3$ rs736775 might contribute to the altered antioxidant capacity in SCZ patients. In this study, we compared allelic and genotypic frequencies of rs 736775 between 617 SCZ patients and 648 controls. However, we observed a TT genotype frequency of $47.32 \%$, a CT genotype frequency of $44.25 \%$, and a CC genotype frequency of $8.43 \%$ for patients with SCZ, compared with 51.08\%, 41.82\%, and $7.10 \%$, respectively, in controls. No significant differences in allelic or genotypic frequencies of GPX3 rs736775 were observed between SCZ patients and controls in our study. This finding suggests that the GPX3 rs736775 polymorphism may not be the genetic risk factor for SCZ patients.

GSTs are encoded by the GST family of genes located on different chromosomes and the cytosolic GST can be classified into four major groups: Alpha, $\mathrm{Mu}, \mathrm{Pi}$, and Theta. The GST Alpha (GSTA) family is located in chromosome 6 and shows an important detoxifying activity that protects the cell from ROS. The GSTA1 rs3957357 is one of the five polymorphisms just located in the promoter region of GSTA1 genes, and its mutant genotype can result in decreased enzyme activity. In recent years, GSTA1 rs3957357 has been reported to be associated with many disorders including bladder cancer, leukemia and gestational hypertension, as well as SCZ. For instance, Rossi et al reported that GSTA1 rs3957357 may associate with event-free survival in patients with diffuse large B-cell lymphoma. ${ }^{21}$ Iorio et al suggested that the GSTA1 rs3957357 was significantly associated with 
gestational hypertension risk. ${ }^{29}$ However, we are intrigued by the effects of GSTA1 polymorphisms on the risk of SCZ. Gravina et al found a higher frequency of the combined genotypes including GSTA1 polymorphisms in Italy patients with SCZ. ${ }^{23}$ Spalletta et al suggested that GSTA1 polymorphisms were associated with the altered microstructure of the thalami in Italy patients with $\mathrm{SCZ}{ }^{24}$ Because of several factors, such as population and sample, it is necessary to test the gene polymorphisms on the risk of some disorders, we sought to analyze the Chinese Han population in the present study. We found GG, AG and AA genotype frequencies of $71.64 \%, 26.90 \%$, and $1.46 \%$ in patients with SCZ, compared with $77.62 \%, 21.45 \%$, and $0.93 \%$, respectively, in controls. Consequently, significant differences in allelic and genotypic frequencies of GSTA1 rs3957357 were detected between SCZ patients and controls. Furthermore, rs3957357 was the risk factor for SCZ on the basis of dominant models. GSTA1 rs3957357 appears to be a potential predictive tool for the Chinese population at risk of SCZ.

In addition, several published studies have shown that gene-gene (G-G) interactions can play important roles in the pathophysiological mechanisms of many complex diseases. $^{30-32}$ In present study, the interaction between the GSTA1 gene and the GPX3 gene was analyzed using GMDR software, ${ }^{26}$ with CV consistency of $10 / 10$ and a $p$ value of 0.0107 . The results showed that the potential gene-gene interaction between GSTA1 and GPX3 was the genetic risk factor for SCZ patients.

\section{Conclusion}

In conclusion, this is the first report to investigate the effects of GPX3 and GSTA1 SNPs in SCZ in a Chinese population. Our results suggest that GSTA1 rs3957357 SNP and the interaction between GSTA1 (rs3957357) and GPX3 (rs736775) have effects on the risk of SCZ and they are potential predictive tools for Chinese population at risk of SCZ. However, most subjects were Han nationality in the Shandong region in our study and the sample size is relatively small, and larger-scale studies are necessary to validate these findings.

\section{Acknowledgments}

We would like to thank the JNMU staff for all the support.

\section{Funding}

This work was supported by the Shandong Provincial Natural Science Foundation of China (Grant no.
ZR2016HL22), the NSFC Cultivation Project of Jining Medical University (2016), the National Undergraduate Innovation and Entrepreneurship Training Program (201810443020), the Shandong Medical and Health Science and Technology Development Project (2015WS0420 and 2017WS338).

\section{Disclosure}

The authors report no conflicts of interest in this work.

\section{References}

1. Gysin R, Kraftsik R, Sandell J, et al. Impaired glutathione synthesis in schizophrenia: convergent genetic and functional evidence. Proc Natl Acad Sci U S A. 2007;104(42):16621-16626. doi:10.1073/ pnas.0706778104

2. Tamminga CA, Holcomb HH. Phenotype of schizophrenia: a review and formulation. Mol Psychiatry. 2005;10(1):27-39. doi:10.1038/sj. mp. 4001563

3. Freedman $\quad$ R. Schizophrenia. $N$ Engl $J$ Med. 2003;349 (18):1738-1749. doi:10.1056/NEJMra035458

4. Thaker GK, Carpenter WT Jr. Advances in schizophrenia. Nat Med. 2001;7(6):667-671. doi:10.1038/89040

5. Mowry BJ, Gratten J. The emerging spectrum of allelic variation in schizophrenia: current evidence and strategies for the identification and functional characterization of common and rare variants. $\mathrm{Mol}$ Psychiatry. 2013;18(1):38-52. doi:10.1038/mp.2012.34

6. Shinkai T, Muller DJ, De Luca V, et al. Genetic association analysis of the glutathione peroxidase (GPX1) gene polymorphism (Pro197Leu) with tardive dyskinesia. Psychiatry Res. 2006;141 (2):123-128. doi:10.1016/j.psychres.2004.06.023

7. Reddy R, Sahebarao MP, Mukherjee S, Murthy JN. Enzymes of the antioxidant defense system in chronic schizophrenic patients. Biol Psychiatry. 1991;30(4):409-412. doi:10.1016/0006-3223(91)90298-Z

8. Gawryluk JW, Wang JF, Andreazza AC, Shao L, Young LT. Decreased levels of glutathione, the major brain antioxidant, in post-mortem prefrontal cortex from patients with psychiatric disorders. Int J Neuropsychopharmacol. 2011;14(1):123-130. doi:10. 1017/S1461145710000805

9. Yao JK, Keshavan MS. Antioxidants, redox signaling, and pathophysiology in schizophrenia: an integrative view. Antioxid Redox Signal. 2011;15(7):2011-2035. doi:10.1089/ars.2010.3603

10. Behrens MM, Sejnowski TJ. Does schizophrenia arise from oxidative dysregulation of parvalbumin-interneurons in the developing cortex? Neuropharmacology. 2009;57(3):193-200. doi:10.1016/j.neuropharm. 2009.06.002

11. Tosic M, Ott J, Barral S, et al. Schizophrenia and oxidative stress: glutamate cysteine ligase modifier as a susceptibility gene. Am J Hum Genet. 2006;79(3):586-592. doi:10.1086/507566

12. Do KQ, Trabesinger AH, Kirsten-Kruger M, et al. Schizophrenia: glutathione deficit in cerebrospinal fluid and prefrontal cortex in vivo. Eur J Neurosci. 2000;12(10):3721-3728. doi:10.1046/j.1460-9568. 2000.00229.x

13. Gawryluk JW, Wang JF, Andreazza AC, Shao L, Yatham LN, Young LT. Prefrontal cortex glutathione S-transferase levels in patients with bipolar disorder, major depression and schizophrenia. Int $J$ Neuropsychopharmacol. 2011;14(8):1069-1074.

14. Kim WS, Wong J, Weickert CS, Webster MJ, Bahn S, Garner B. Apolipoprotein-D expression is increased during development and maturation of the human prefrontal cortex. J Neurochem. 2009;109 (4):1053-1066. doi:10.1111/jnc.2009.109.issue-4 
15. Wang JY, Yang IP, Wu DC, Huang SW, Wu JY, Juo SH. Functional glutathione peroxidase 3 polymorphisms associated with increased risk of Taiwanese patients with gastric cancer. Clin Chim Acta. 2010;411(19-20):1432-1436. doi:10.1016/j.cca.2010.05.026

16. Noci S, Dugo M, Bertola F, et al. A subset of genetic susceptibility variants for colorectal cancer also has prognostic value. Pharmacogenomics J. 2016;16(2):173-179. doi:10.1038/tpj.2015.35

17. Zhang H, Zhao W, Gu D, et al. Association of antioxidative enzymes polymorphisms with efficacy of platin and fluorouracil-based adjuvant therapy in gastric cancer. Cell Physiol Biochem. 2018;48 (6):2247-2257. doi:10.1159/000492642

18. Fullerton JM, Tiwari Y, Agahi G, et al. Assessing oxidative pathway genes as risk factors for bipolar disorder. Bipolar Disord. 2010;12 (5):550-556. doi:10.1111/bdi.2010.12.issue-5

19. Bjork K, Saarikoski ST, Arlinde C, et al. Glutathione-S-transferase expression in the brain: possible role in ethanol preference and longevity. FASEB J. 2006;20(11):1826-1835. doi:10.1096/fj.06-5896com

20. Hayes JD, Flanagan JU, Jowsey IR. Glutathione transferases. Annu Rev Pharmacol Toxicol. 2005;45:51-88. doi:10.1146/annurev. pharmtox.45.120403.095857

21. Rossi D, Rasi S, Franceschetti S, et al. Analysis of the host pharmacogenetic background for prediction of outcome and toxicity in diffuse large B-cell lymphoma treated with R-CHOP21. Leukemia. 2009;23(6):1118-1126. doi:10.1038/leu.2008.398

22. Akhdar H, El Shamieh S, Musso O, et al. The rs3957357C $>$ T SNP in GSTA1 is associated with a higher risk of occurrence of hepatocellular carcinoma in european individuals. PLoS One. 2016;11(12): e0167543. doi:10.1371/journal.pone. 0167543

23. Gravina P, Spoletini I, Masini S, et al. Genetic polymorphisms of glutathione S-transferases GSTM1, GSTT1, GSTP1 and GSTA1 as risk factors for schizophrenia. Psychiatry Res. 2011;187(3):454-456. doi:10.1016/j.psychres.2010.10.008
24. Spalletta G, Piras F, Gravina P, Bello ML, Bernardini S, Caltagirone C. Glutathione S-transferase alpha 1 risk polymorphism and increased bilateral thalamus mean diffusivity in schizophrenia. Psychiatry Res. 2012;203(2-3):180-183. doi:10.1016/j.pscychresns. 2011.12.016

25. Gao H, Liu C, Song S, et al. GPX1 Pro198Leu polymorphism and GSTP1 Ile105Val polymorphisms are not associated with the risk of schizophrenia in the Chinese Han population. Neuroreport. 2017;28 (15):969-972. doi:10.1097/WNR.0000000000000870

26. Lou XY, Chen GB, Yan L, et al. A generalized combinatorial approach for detecting gene-by-gene and gene-by-environment interactions with application to nicotine dependence. Am J Hum Genet. 2007;80(6):1125-1137. doi:10.1086/518312

27. Hu YJ, Diamond AM. Role of glutathione peroxidase 1 in breast cancer: loss of heterozygosity and allelic differences in the response to selenium. Cancer Res. 2003;63(12):3347-3351.

28. Kraus S, Hummler S, Toriola AT, et al. Impact of genetic polymorphisms on adenoma recurrence and toxicity in a COX2 inhibitor (celecoxib) trial: results from a pilot study. Pharmacogenet Genomics. 2013;23(8):428-437. doi:10.1097/FPC.0b013e3283631 784

29. Iorio A, Spinelli M, Polimanti R, et al. GSTA1 gene variation associated with gestational hypertension and its involvement in pregnancy-related pathogenic conditions. Eur $J$ Obstet Gynecol Reprod Biol. 2015;194:34-37. doi:10.1016/j.ejogrb.2015.08.006

30. Yoshimaru T, Komatsu M, Matsuo T, et al. Targeting BIG3-PHB2 interaction to overcome tamoxifen resistance in breast cancer cells. Nat Commun. 2013;4:2443. doi:10.1038/ncomms3443

31. Steen KV. Travelling the world of gene-gene interactions. Brief Bioinform. 2012;13(1):1-19. doi:10.1093/bib/bbr012

32. Wu M, Ma S. Robust genetic interaction analysis. Brief Bioinform. 2019;20(2):624-637. doi:10.1093/bib/bby033
Neuropsychiatric Disease and Treatment

\section{Publish your work in this journal}

Neuropsychiatric Disease and Treatment is an international, peerreviewed journal of clinical therapeutics and pharmacology focusing on concise rapid reporting of clinical or pre-clinical studies on a range of neuropsychiatric and neurological disorders. This journal is indexed on PubMed Central, the 'PsycINFO' database and CAS, and is the official journal of The International Neuropsychiatric Association (INA). The manuscript management system is completely online and includes a very quick and fair peer-review system, which is all easy to use. Visit http://www.dovepress.com/testimonials.php to read real quotes from published authors. 